\title{
I5-Deoxy- $\Delta^{12,14}$-prostaglandin $J_{2}$ as a potential regulator of bone metabolism via PPAR $\gamma$ - dependent and independent pathways: a review
}

This article was published in the following Dove Press journal:

Drug Design, Development and Therapy

\author{
Zhencheng Xiong ${ }^{1,2}$ \\ Pan Luo' \\ Jun Zhou ${ }^{2,3}$ \\ Mingsheng $\operatorname{Tan}^{1-3}$ \\ 'Graduate School of Peking Union \\ Medical College, Chinese Academy of \\ Medical Sciences, Beijing, People's \\ Republic of China; ${ }^{2}$ Department of Spine \\ Surgery, China-Japan Friendship Hospital, \\ Beijing, People's Republic of China; \\ ${ }^{3}$ School of Clinical Medicine, Graduate \\ School of Beijing University of Chinese \\ Medicine, Beijing, People's Republic of \\ China
}

\begin{abstract}
Bone metabolism is a complex physiological process that primarily involves osteoblast-mediated bone formation and osteoclast-mediated bone resorption, both of which are regulated by a variety of biological factors. There is increasing evidence that peroxisome proliferator-activated receptor $\gamma(\operatorname{PPAR} \gamma)$ is a member of the nuclear receptor superfamily and plays an important role in lipid metabolism and bone metabolism. Through the PPAR $\gamma$-dependent pathway, 15-deoxy- $\Delta^{12,14}$-prostaglandin $\mathrm{J}_{2}\left(15 \mathrm{~d}-\mathrm{PGJ}_{2}\right)$ promotes the formation of marrow adipocytes and inhibits the formation of osteoblasts, resulting in bone loss and increasing the risk of fracture and osteoporosis. Recent studies have found that through the PPAR $\gamma$-independent pathway, $15 \mathrm{~d}-\mathrm{PGJ}_{2}$ plays a regulatory role in bone metastasis of breast cancer, which can inhibit osteoclastogenesis and reduce bone destruction. The purpose of our review is to summarize the recent progress in elucidating the mechanisms and effects of $15 \mathrm{~d}_{-} \mathrm{PGJ}_{2}$ in bone metabolism, which can serve as a novel therapeutic target for bone tumors, osteoporosis, rheumatoid arthritis (RA), and other bone diseases.
\end{abstract}

Keywords: bone metabolism, osteoblast, adipogenesis, osteoporosis, rheumatoid arthritis, bone metastasis

\section{Introduction}

Bone is a dynamically changing tissue that constantly adapts to vertebrate life to maintain bone shape, size, and structural integrity, and bone regulates mineral homeostasis in the body. ${ }^{1}$ Bone formation and bone resorption are mediated by osteoblasts and osteoclasts, respectively, which are the two main processes of bone metabolism. ${ }^{2}$ Formation and resorption are tightly coupled under physiological conditions to maintain bone mass. In the pathological process of osteoporosis, bone resorption exceeds bone formation and can cause an imbalance in bone metabolism and a net loss of bone. ${ }^{3}$ The bone marrow stroma includes mesenchymal stem cells (MSCs) and hematopoietic stem cells (HSCs), which can differentiate into a variety of cell types common to bone. ${ }^{4}$ Two main types of cells in bone have different developmental origins: osteoblasts are derived from mesenchymal lineage, ${ }^{5}$ and osteoclasts are derived from hematopoietic lineage. ${ }^{6}$ Many biological factors regulate osteoblast differentiation and osteoclast differentiation, thus affecting bone formation and bone resorption and playing a role in bone metabolism.

Prostaglandins (PGs) are a class of bioactive compounds produced by arachidonic acid (AA) that have a variety of regulatory functions in the human body. ${ }^{7}$ Different types of PGs have complex functions in different target cells. ${ }^{8} 15 \mathrm{~d}_{-} \mathrm{PGJ}_{2}$ is an
Department of Spine Surgery, China-Japan Friendship Hospital, No. 2 Yinghua Dongjie, Hepingli, Chaoyang District, Beijing, People's Republic of China Tel +86I39l 1025605

Email zrtanms@163.com 
endogenous ligand for PPAR $\gamma$, which is produced by the cyclooxygenase (COX)-mediated AA metabolism pathway. ${ }^{8-10}$ Studies have shown that ligand-activated PPAR $\gamma$ alters the fate of bone marrow MSCs by promoting the differentiation of adipocytes and inhibiting the differentiation of osteoblasts. ${ }^{11-13}$ Numerous studies have confirmed that $15 \mathrm{~d}-\mathrm{PGJ}_{2}$ promotes the differentiation of adipocytes and inhibits the differentiation of osteoblasts by activating $\operatorname{PPAR} \gamma$, thereby inhibiting bone formation and causing bone loss. ${ }^{9,10}$ Recently, studies have shown that through a PPAR $\gamma$-independent pathway, $15 \mathrm{~d}_{-} \mathrm{PGJ}_{2}$ inhibits bone destruction caused by bone metastasis in breast cancer by suppressing osteoclast differentiation and bone resorption. ${ }^{14}$ Treatment with $15 \mathrm{~d}-\mathrm{PGJ}_{2}$ also inhibits bone loss caused by estrogen deficiency. ${ }^{14} 15 \mathrm{~d}-\mathrm{PGJ}_{2}$ may be a potential regulator of bone metabolism, and drugs targeting $15 \mathrm{~d}_{-} \mathrm{PGJ}_{2}$ may offer new prospects for metabolic bone diseases. To further explore these prospects, this review was performed.

\section{The biosynthesis and bioactivity of I5d-PG $\mathbf{J}_{2}$}

The biosynthesis of $15 \mathrm{~d}-\mathrm{PGJ}_{2}$ is based on the continuous action of several enzymes, the general pathway of which is illustrated in Figure 1. ${ }^{15}$ Under the action of enzyme phospholipase $\mathrm{A}_{2}\left(\mathrm{PLA}_{2}\right)$, AA is released by membrane phospholipids as the first step of this metabolic pathway. ${ }^{8,15}$ Under the action of COX-1 or COX-2, AA first produces $\mathrm{PGG}_{2}$ and then $\mathrm{PGH}_{2}{ }^{8,16} \mathrm{PGH}_{2}$ is an unstable intermediate that can be converted into a series of stable prostaglandins by their specific prostaglandin synthases, including $\mathrm{PGD}_{2}, \mathrm{PGE}_{2}, \mathrm{PGF}_{2 \alpha}, \mathrm{PGI}_{2}$, and thromboxane $\mathrm{A}_{2} \cdot{ }^{16,17} \mathrm{PGD}_{2}$ is synthesized under the action of prostaglandin D synthase (PTGDS, including H-PTGDS and L-PTGDS). ${ }^{18,19}$ Subsequently, PGD $_{2}$ readily undergoes chemical dehydration, which in turn forms the cyclopentenone prostaglandin $\mathrm{PGJ}_{2} \cdot{ }^{9,20}$ Both $15 \mathrm{~d}-\mathrm{PGJ}_{2}$ and $\Delta^{12}-\mathrm{PGJ}_{2}$ are produced by $\mathrm{PGJ} 2$, but the latter requires the participation of albumin. ${ }^{21}$

Unlike other types of PGs, $15 \mathrm{~d}-\mathrm{PGJ}_{2}$ contains a cyclopentenone ring structure. ${ }^{8}$ The cyclopentenone ring has an electrophilic $\alpha, \beta$-unsaturated ketone moiety that provides a unique bioactivity spectrum for $15 \mathrm{~d}-\mathrm{PGJ}_{2}$. ${ }^{22}$ In 1995, Forman and Tontonoz ${ }^{9}$ examined the ability of AA metabolites to act as ligands to activate PPAR $\gamma$ and identified $15 \mathrm{~d}_{-} \mathrm{PGJ}_{2}$ as its natural ligand. Although $15 \mathrm{~d}-$ $\mathrm{PGJ}_{2}$ has a lower affinity for PPAR $\gamma$ than steroid hormones for its homologous intracellular receptors, it is the highest

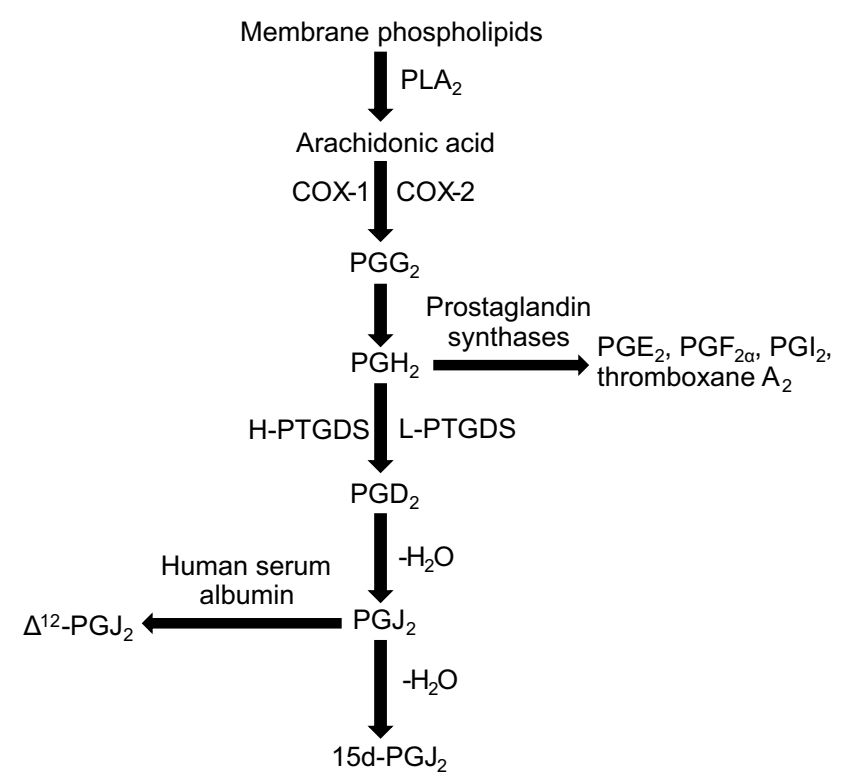

Figure I Biosynthesis of $15 \mathrm{~d}-\left.\mathrm{PG}\right|_{2}$. In the first step, membrane phospholipids are catalyzed by the action of the PLA 2 enzyme to release AA. In the second step, AA is sequentially metabolized to $\mathrm{PGG}_{2}$ and then to $\mathrm{PGH}_{2}$ by COX-I or COX-2. Subsequently, $\mathrm{PGD}_{2}, \mathrm{PGE}_{2}, \mathrm{PGF}_{2 a}, \mathrm{PGI}_{2}$, and thromboxane $\mathrm{A}_{2}$ were converted from $\mathrm{PGH}_{2}$ by their respective prostaglandin synthetase. The rate-limiting enzyme used to synthesize PGD 2 is PTGDS, both H-PTGDS and L-PTGDS. PGD 2 readily undergoes chemical dehydration, losing water to form the cyclopentenone prostaglandin $P G J_{2}$. In the final step, $15 d-P G J_{2}$ and $\Delta^{12}-P G J_{2}$ are produced from $P G J_{2}$ by albuminindependent and albumin-dependent reactions, respectively.

Abbreviations: $15 \mathrm{~d}-\mathrm{PG} \mathrm{J}_{2}, 15-$ deoxy- $\Delta^{12,14}$-prostaglandin $\mathrm{J}_{2}$; PLA 2 , phospholipase $\mathrm{A}_{2}$; AA, arachidonic acid; PG, prostaglandin; COX, cyclooxygenase; PTGDS, prostaglandin $D$ synthase.

affinity natural ligand of PPAR $\gamma$ identified to date. ${ }^{8}$ Due to its specific cyclopentenone ring structure and ligand activity that activates PPAR $\gamma, 15 \mathrm{~d}_{-} \mathrm{PGJ}_{2}$ plays a regulatory role in many physiological and disease processes. Studies have shown that $15 \mathrm{~d}-\mathrm{PGJ}_{2}$ promotes apoptosis ${ }^{23,24}$ and exerts anti-inflammatory, ${ }^{16}$ anti-angiogenic, ${ }^{24,25}$ anti-metastatic, 14 and even anticancer ${ }^{25-27}$ effects in animals.

\section{$[5 \mathrm{~d}-\mathbf{P G}]_{2}$ regulates adipocyte differentiation and osteoblast differentiation via a PPAR $\gamma$ - dependent pathway}

MSCs in the bone marrow are capable of differentiating into a variety of cell types, such as osteoblasts, adipocytes, chondrocytes, fibroblasts, or myocytes. ${ }^{5}$ Each phenotypic transition requires a rigid, uninterrupted, and asynchronous program of gene expression. ${ }^{3}$ Osteoblasts are involved in the construction of the organic and inorganic components of bone. ${ }^{28}$ Recent gene deletion studies have shown that osteoblast differentiation requires a complex sequence of processes to activate transcription factors involved in 
osteoblastogenesis (including Wnt/ $\beta$-catenin, Runt-related transcription factor 2 (Runx2), and Osterix) and to suppress transcription factors involved in adipogenesis (including PPAR $\gamma$ and CCAAT/enhancer binding protein $(\mathrm{C} / \mathrm{EBP})) .{ }^{11,29}$ The key factors in the process of MSC adipogenic and osteogenic lineage differentiation are PPAR $\gamma$ and Wnt, respectively. ${ }^{11}$

PPAR $\gamma$, which acts as a nuclear receptor, contains a central DNA-binding domain and a C-terminal ligandbinding domain. ${ }^{30}$ Under the strict regulation of many transcription factors such as $\operatorname{PPAR} \gamma$ and $\mathrm{C} / \mathrm{EBP} \alpha / \beta / \delta$, adipogenesis is achieved. ${ }^{31}$ Numerous studies have shown that after $15 \mathrm{~d}-\mathrm{PGJ}_{2}$ binds to PPAR $\gamma$, transcription begins with the involvement of coregulators called corepressors and coactivators. ${ }^{9,10}$ When $15 \mathrm{~d}-\mathrm{PGJ}_{2}$ is absent, PPAR $\gamma$ forms a protein complex with corepressors such as silencing mediator for retinoid or thyroid-hormone receptors (SMRT), NCoR, and histone deacetylases, which transcriptionally silence PPAR $\gamma{ }^{32}$ Upon $15 \mathrm{~d}^{3}-\mathrm{PGJ}_{2}$ binding, corepressors dissociate from the heterodimer of PPAR $\gamma$ and retinoid $\mathrm{X}$ receptor (RXR) that were previously bound to DNA sequences in the promoter regions (called PPAR-response elements (PPRE)), thereby allowing PPAR $\gamma$ to recruit coactivators and initiate the transcription of adipocyte genes. ${ }^{33}$ With or without ligand binding, PPAR $\gamma$ still binds to target genes (Figure 2). ${ }^{34}$ The process of PPAR $\gamma$ regulation of target gene expression is regulated by histone modification. ${ }^{35}$ Research has shown that the transcriptional activity of PPAR $\gamma$ is inhibited by phosphorylation of serine residue 112 on the $\mathrm{N}$ terminus ${ }^{31}$ and SUMOylation of lysine $107 .^{36}$ Nocturnin is a circadianregulated protein that has been shown to control preadipocyte differentiation and regulate lipid metabolism through the modulation of PPAR $\gamma$ activity. ${ }^{37} 15 \mathrm{~d}-\mathrm{PGJ}_{2}$ is an endogenous natural ligand for PPAR $\gamma$ that regulates adipocyte differentiation by activating $\operatorname{PPAR} \gamma$, and coregulators that affect the expression of PPAR $\gamma$ may also regulate this process. These studies indirectly indicate that $15 \mathrm{~d}-\mathrm{PGJ}_{2}$ is a potential regulator of bone marrow adipocyte differentiation via a PPAR $\gamma$-dependent pathway.

Emerging evidence suggests that Wnt ligands play a role in promoting osteoblastogenesis through canonical and noncanonical signaling pathways. ${ }^{13,38}$ The Wnt/ $\beta$ catenin signaling pathway, commonly known as the canonical pathway, inhibits the formation of adipocytes by reducing the expression of $\operatorname{PPAR} \gamma$ and $\mathrm{C} / \mathrm{EBP} \alpha$ mRNA. ${ }^{39,40}$ Wnt5a acts as a noncanonical Wnt ligand to suppresses adipogenesis by inhibiting the transcriptional activity of PPAR $\gamma$ and subsequently activating the histone methyltransferase SETDB1. ${ }^{11}$ Studies have also found that PPAR $\gamma$ deficiency induces osteoblastogenesis resulting in an increase in bone mass. ${ }^{41}$ Adipocyte differentiation and

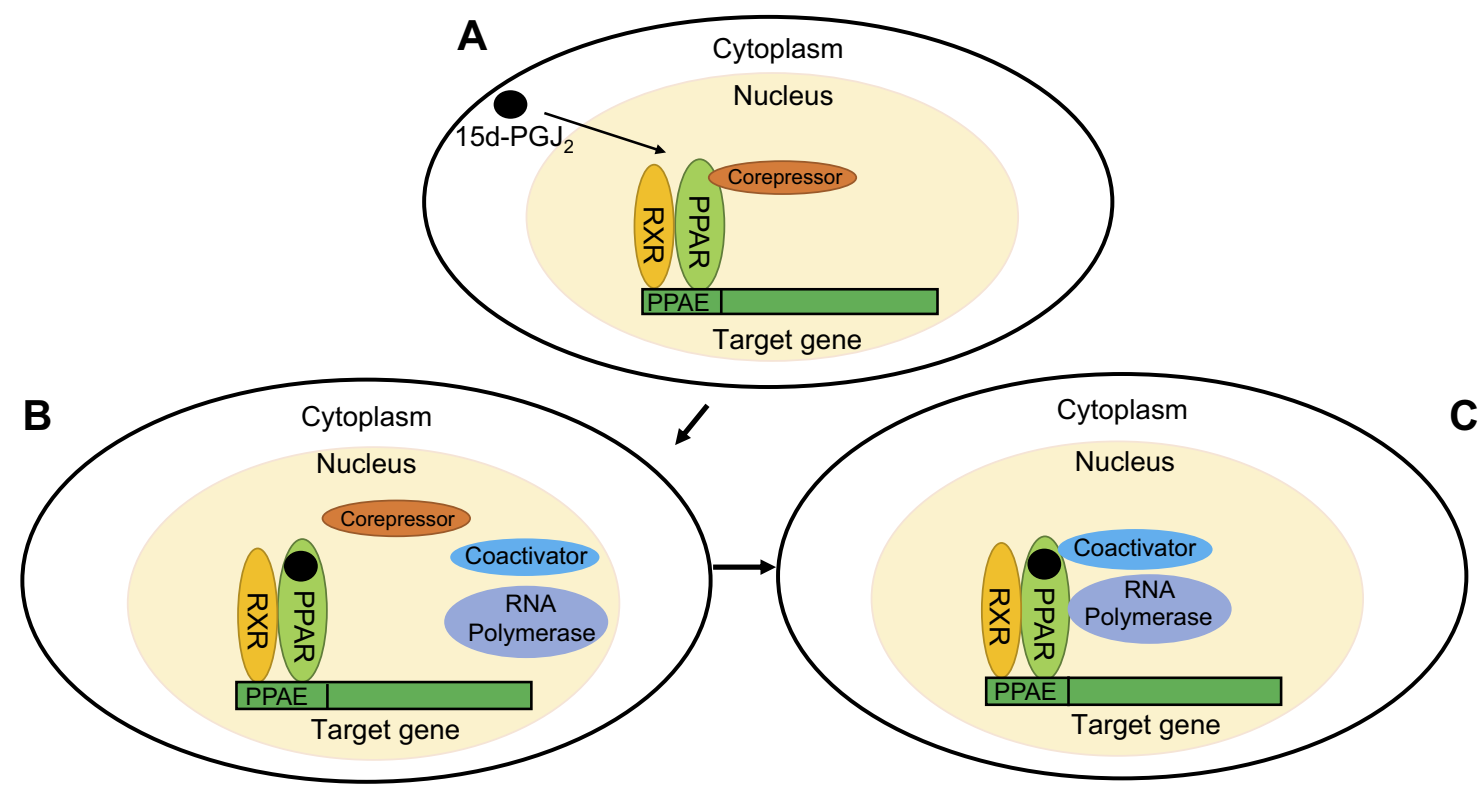

Figure 2 Regulation of target gene expression by binding of I5d-PGJ $\left.\right|_{2}$ to PPAR $\gamma$. (A) PPAR $\gamma$ forms a heterodimer with RXR to recognize PPRE in the promoter region of target genes. When the PPAR $\gamma$ ligand is absent, PPAR $\gamma$ forms a protein complex with corepressors, thus transcriptionally silencing PPAR $\gamma$. (B) I5d-PG ${ }_{2}$ is an endogenous ligand for PPAR $\gamma$ that binds to PPAR $\gamma$ resulting in PPAR $\gamma$ dissociation from a corepressor. (C) Upon binding of $15 \mathrm{~d}-\mathrm{PG} \mathrm{J}_{2}$ to the natural ligand, PPAR $\gamma$ can recruit coactivators and RNA polymerase to stimulate transcription of target genes.

Abbreviations: $R X R$, retinoid $X$ receptor; PPRE, PPAR-response elements. 
osteoblast differentiation are affected by both the PPAR $\gamma$ and Wnt pathways, and $15 \mathrm{~d}-\mathrm{PGJ}_{2}$, an endogenous ligand for $\operatorname{PPAR} \gamma$, is also involved in this regulatory process (Figure 3 ). These findings indicate that $15 \mathrm{~d}-\mathrm{PGJ}_{2}$ promotes bone marrow adipogenesis and inhibits osteoblastogenesis via a PPAR $\gamma$-dependent pathway, thereby reducing bone formation in bone metabolism.

\section{Role of $15 \mathrm{~d}-\mathrm{PGJ}_{2}$ in osteoporosis}

Osteoporosis is a serious social problem whose underlying mechanism is an imbalance between bone formation and bone resorption that increases the propensity of fragility fractures. ${ }^{42}$ Osteoporosis has multiple risk factors, including old age, menopause in women, long-term use of glucocorticoids, a history of fragility fractures, and a history of smoking. ${ }^{42,43}$ The imbalance between adipogenesis and osteoblastogenesis in the pathogenesis of primary or secondary osteoporosis may be related to the activation of PPAR $\gamma .{ }^{41,44-46}$

Studies have shown that the expression of PPAR $\gamma$ in the bone marrow microenvironment increases with age. ${ }^{46}$ Between 20 and 65 years of age, the trabecular volume decreased by $10 \%$, while the volume of adipose tissue increased by $45 \%{ }^{47}$ In the third decade of human life, adipose tissue occupies the femoral cavity, and in the seventh or eighth decade, fat can occupy the vertebrae. ${ }^{48}$ An increasing number of studies have confirmed that the application of glucocorticoids produces significant intramedullary fatty infiltration. ${ }^{49}$ Research has shown that glucocorticoids stimulate the differentiation of MSCs into adipocytes and promote the accumulation of fat by decreasing the expression of type I collagen and osteocalcin mRNA, thereby inhibiting osteoblast differentiation. ${ }^{50} \mathrm{Li}$ et $\mathrm{al}^{51}$ demonstrated that glucocorticoids reduced Cbfa1/Runx2 gene expression by $50-60 \%$, while PPAR $\gamma$ gene expression was increased by $200 \%$.

In one study, Guo et $\mathrm{al}^{52}$ demonstrated that estrogen inhibited the formation of osteoclasts and bone resorption via microRNA-27a targeting of PPAR $\gamma$. This study also showed that in postmenopausal women, estrogen deficiency reduced microRNA-27a expression and increased PPAR $\gamma$ expression, which in turn leads to loss of bone mass and even osteoporosis. ${ }^{52}$ These studies indicate that PPAR $\gamma$ is highly expressed in age-related osteoporosis, glucocorticoid-induced osteoporosis, and postmenopausal osteoporosis, and its activators promote adipogenesis and inhibit osteoblastogenesis. ${ }^{4,51,52}$

Bisphosphonate is an important drug for the prevention and treatment of osteoporosis in clinical applications. ${ }^{53}$ Bisphosphonates not only inhibit bone resorption by directly inhibiting mineral dissolution but also inhibit cell viability by directly acting on osteoclasts and interfering with specific cellular biochemical processes. ${ }^{53}$ Studies have shown that ligand-activated PPAR $\gamma$ leads to

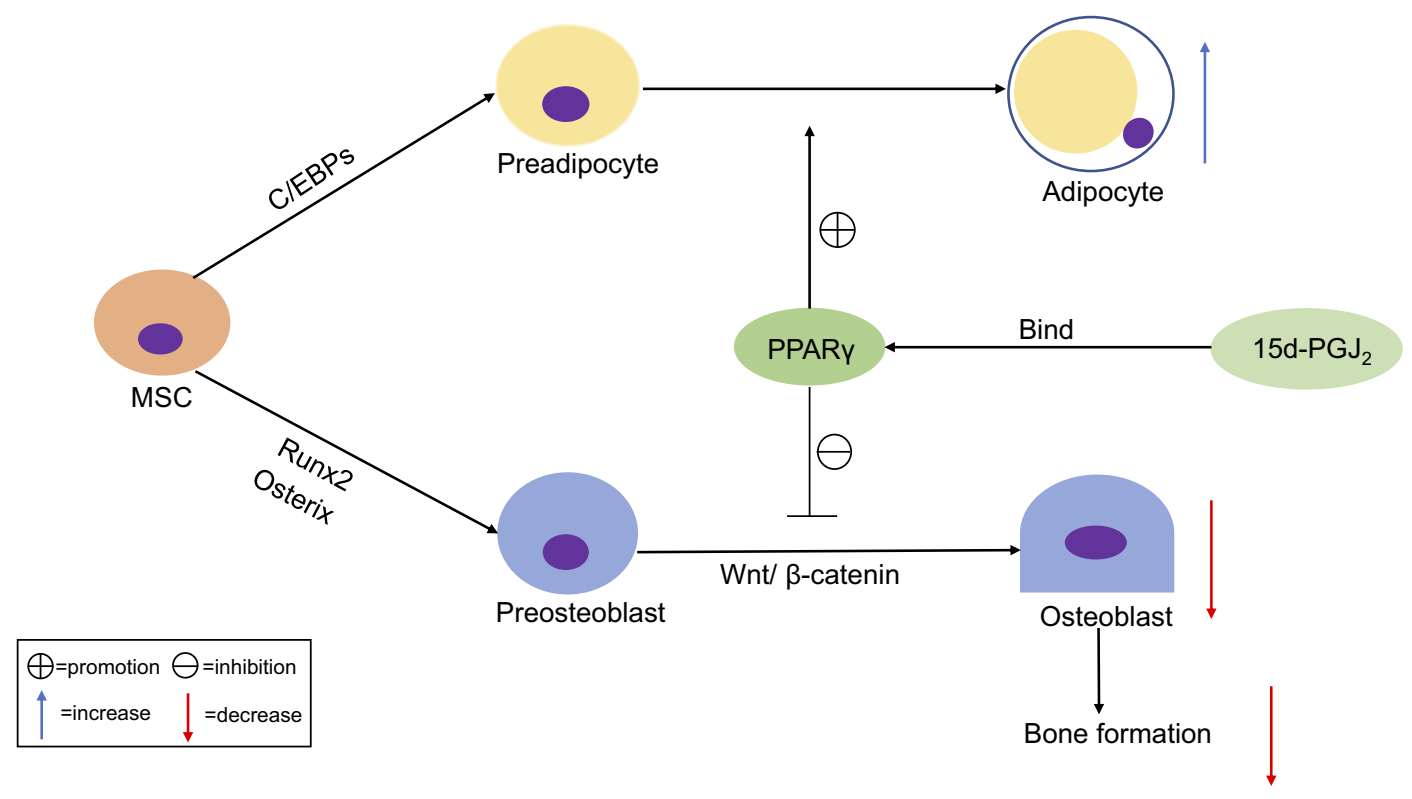

Figure $3 \quad[5 d-P G]_{2}$ regulates adipocyte differentiation and osteoblast differentiation via a PPAR $\gamma$-dependent pathway. MSCs have the potential to differentiate towards adipocytes and osteoblasts, through multiple factors and extracellular signaling pathways. Adipogenesis occurs under the strict regulation of multiple transcription factors, including PPAR $\gamma$ and C/EBPs, and osteoblastogenesis occurs under the regulation of Runx2, Osterix, and Wnt/ $\mathbf{\beta}$-catenin. Activation of PPAR $\gamma$ by $15 \mathrm{~d}-\mathrm{PG} \mathrm{J}_{2}$ and other synthetic ligands can promote adipogenesis but suppress osteoblastogenesis, resulting in the inhibition of bone formation.

Abbreviations: MSCs, mesenchymal stem cells; C/EBPs, CCAAT/enhancer binding proteins; Runx2, runt-related transcription factor 2. 
osteoporosis by promoting adipocyte differentiation and inhibiting osteoblast differentiation. ${ }^{51,52}$ In vivo, $15 \mathrm{~d}$ $\mathrm{PGJ}_{2}$, as an endogenous ligand for PPAR $\gamma$, may have an important regulatory role in the pathogenesis of osteoporosis in the absence of PPAR $\gamma$ synthetic agonists. However, research on the therapeutic advantages of $15 \mathrm{~d}-\mathrm{PGJ}_{2}$ compared with traditional drugs is limited.

\section{I5d-PG] $]_{2}$ regulates osteoclast differentiation via PPAR $\gamma$ - independent and/or PPAR $\gamma$ - dependent pathways}

Osteoclasts are involved in the removal of organic and inorganic bone components. ${ }^{29}$ Receptor activator of NF- $\mathrm{\kappa B}$ ligand (RANKL) regulates the activity of osteoclasts by binding to receptor activator of NF- $\kappa \mathrm{B}$ (RANK) on its surface. ${ }^{54}$ Osteoprotegerin (OPG) is a decoy receptor for RANKL and belongs to the tumor necrosis factor (TNF) receptor superfamily, which blocks the effects of RANKL. ${ }^{54}$ Differentiation of osteoclasts requires coordinated regulation of transcription factors such as c-fos, c-jun and nuclear factor of activated T-cells, cytoplasmic 1 (NFATc1). ${ }^{1}$ Studies have shown that OPG does not inhibit the process by which TNF- $\alpha$ promotes the formation of osteoclasts in humans. ${ }^{55}$ In one study, Hounoki et $\mathrm{al}^{56}$ found that $15 \mathrm{~d}-\mathrm{PGJ}_{2}$ inhibited osteoclast differentiation induced by TNF- $\alpha$ through the PPAR $\gamma$ independent pathway. $15 \mathrm{~d}-\mathrm{PGJ}_{2}$ and ciglitazone, both of which are PPAR $\gamma$ agonists, were found to inhibit TNFmediated osteoclast differentiation. The addition of the PPAR $\gamma$ antagonist, GW9662, to the culture rescued the inhibition induced by ciglitazone, but did not affect the inhibition induced by $15 \mathrm{~d}_{-} \mathrm{PGJ}_{2}{ }^{56}{ }^{5}$ RANKL-induced monocyte chemoattractant protein-1 (MCP-1) has been shown to play an important role in osteoclast differentiation. ${ }^{57}$ In this study, $15 \mathrm{~d}_{-} \mathrm{PGJ}_{2}$ reduced MCP-1, thereby inhibiting osteoclast differentiation induced by TNF- $\alpha{ }^{57}$ Considering the pivotal role of TNF- $\alpha$ in inflammatory joints, $15 \mathrm{~d}-\mathrm{PGJ}_{2}$ appears to be a promising targeting factor for the treatment of inflammatory bone resorption diseases such as rheumatoid arthritis (RA). ${ }^{58}$ A series of studies have shown that $15 \mathrm{~d}_{-} \mathrm{PGJ}_{2}$ may play an important role in osteoclast differentiation via a PPAR $\gamma$-independent pathway, whereas ciglitazone acts via a PPAR $\gamma$-dependent pathway.

\section{[5d-PG $]_{2}$ is an important inflammatory mediator in RA}

RA is a chronic disease affecting multiple joints that is accompanied by inflammation, massive synovial membranes, and neovascularization. ${ }^{59} \mathrm{PGE}_{2}$ plays an important regulatory role in RA by inducing joint erosion and synovial inflammation. ${ }^{60}$ $15 \mathrm{~d}^{-} \mathrm{PGJ}_{2}$ is also a key negative regulator of the AA metabolism pathway and exerts an anti-inflammatory effect. ${ }^{15}$ An earlier clinical study in 2001 showed that $15 \mathrm{~d}_{-} \mathrm{PGJ}_{2}$ inhibited the synthesis of $\mathrm{PGE}_{2}$ induced by interleukin-1 (IL)-1 $\beta$ in rheumatoid synovial fibroblasts by downregulating COX-2 and cPLA $_{2}$ expression. $^{61} 15 \mathrm{~d}-\mathrm{PGJ}_{2}$ has been suggested to be an important inflammatory mediator with potential for the treatment of RA. ${ }^{23}$ The accumulated data suggest that $15 \mathrm{~d}-$ $\mathrm{PGJ}_{2}$ and a portion of synthetic PPAR $\gamma$ agonists inhibit inflammation in models of arthritis, ${ }^{23}$ inflammatory bowel disease, ${ }^{62}$ ischemia-reperfusion injury, ${ }^{63}$ lupus nephritis, ${ }^{64}$ and Alzheimer's disease. ${ }^{65}$

The anti-inflammatory activity of $15 \mathrm{~d}-\mathrm{PGJ}_{2}$ has been proven in many studies, but some studies have also found it to have pro-inflammatory properties. ${ }^{15,66,67}$ Glucocorticoids have also had a crucial role in the regression of inflammation through the intracellular glucocorticoid receptor (GR). ${ }^{68}$ Recent studies have shown that $15 \mathrm{~d}-\mathrm{PGJ}_{2}$ transiently attenuates GR signaling in monocytes/macrophages through a mechanism that relies on the interaction of the cyclopentenone ring in $15 \mathrm{~d}-\mathrm{PGJ}_{2}$ with a cysteine residue in the components of the GR activation pathway. ${ }^{66}$ The regulation of GR sensitivity by $15 \mathrm{~d}-\mathrm{PGJ}_{2}$ requires the participation of SUMOylation. ${ }^{67}$ The effect of the pro-inflammatory properties of $15 \mathrm{~d}-\mathrm{PGJ}_{2}$ on the therapeutic effect of AA still requires further study.

\section{Role of $15 \mathrm{~d}-\mathrm{PG} \mathrm{J}_{2}$ in bone tumors}

Bone metastasis is a type of cancer metastasis that results from primary tumor invasion to the bone, mainly osteolytic metastasis, which leads to an imbalance in bone metabolism. ${ }^{69}$ Breast cancer can metastasize to the bone, causing bone damage and ultimately leading to bone loss. ${ }^{70}$ In one study, Kim et $\mathrm{al}^{14}$ found that through a PPAR $\gamma$-independent pathway, $15 \mathrm{~d}_{-} \mathrm{PGJ}_{2}$ dose-dependently inhibited the RANKL/OPG ratio and osteoclast differentiation, which in turn reduced the formation of absorbed pits by inhibiting the activities of cathepsin $\mathrm{K}$ and matrix metalloproteinase (MMP)-2/9 (Figure 4). Osteolytic factors derived from breast cancer cells include parathyroid hormone-related protein (PTHrP) and some interleukins (mainly IL-6, IL-8). ${ }^{69,71}$ PTHrP enhances osteoclastogenesis and the activity of mature osteoclasts by upregulating RANKL and downregulating OPG in osteoblasts. ${ }^{69,72}$ OPG regulates bone resorption by inhibiting osteoclast activation and final differentiation and by inducing apoptosis in osteoclasts. $^{73}$ Previous studies showed that transforming 


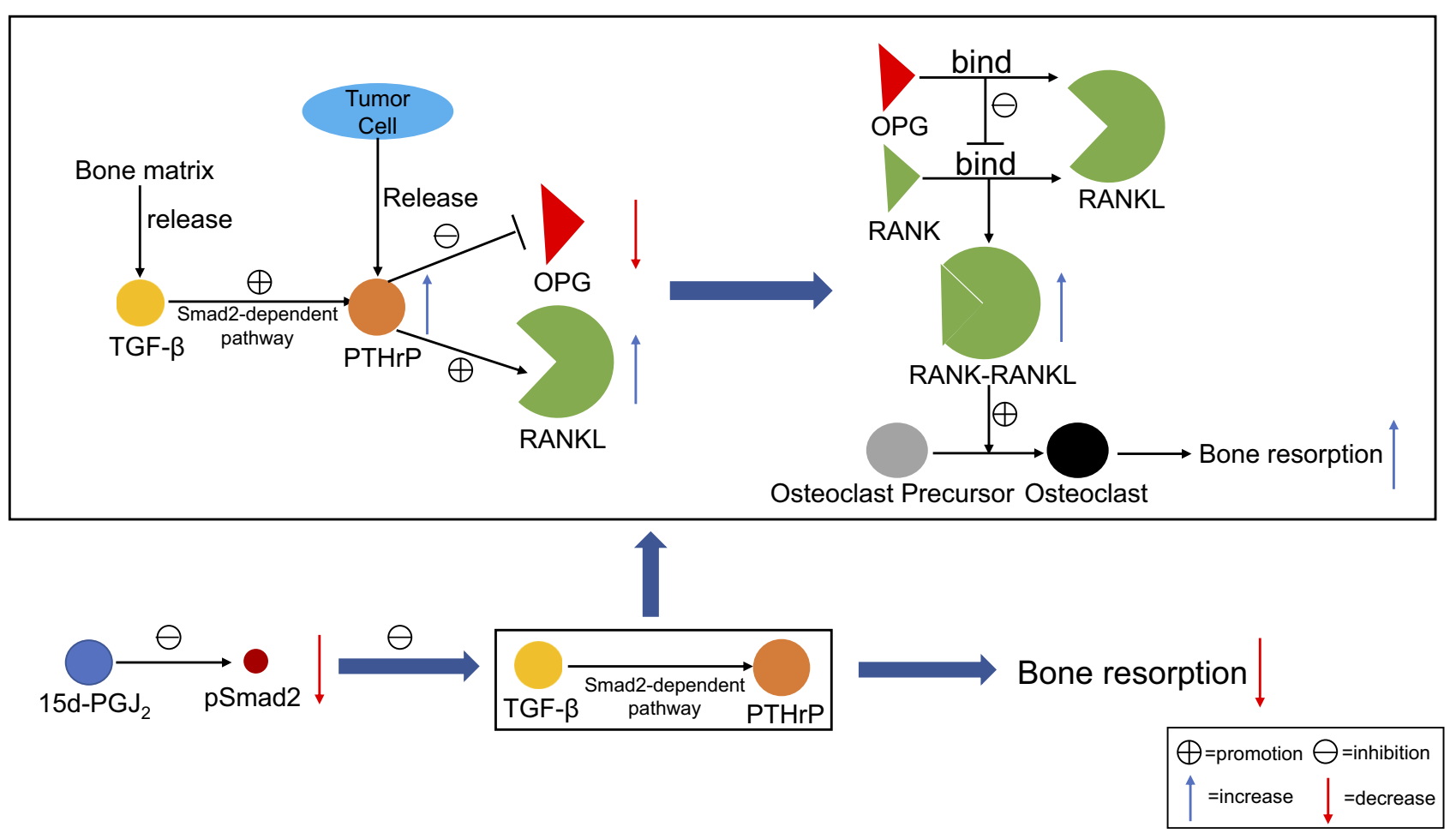

Figure 4 Regulation of $15 d-P G]_{2}$ in bone metastasis of breast cancer. TGF- $\beta$ is released from the bone matrix. PTHrP is an osteolytic factor derived from breast cancer cells. TGF- $\beta$ increases the expression of PTHrP via Smad-dependent or Smad-independent pathways. PTHrP enhances osteoclastogenesis by upregulating RANKL and downregulating OPG in osteoblasts. Studies have shown that $15 d-P G J_{2}$ inhibits PTHrP production via PPAR $\gamma$-independent and Smad2-dependent pathways, thereby regulating osteolytic metastasis. This reduces the RANKL/OPG ratio and is beneficial for increasing the formation of osteoclasts. OPG is a decoy receptor for RANKL, which inhibits the association of RANK and RANKL, thereby inhibiting the production of RANK-RANKL. $15 \mathrm{~d}-\mathrm{PG} \mathrm{J}_{2}$ reduces the production of RANK-RANKL, thereby inhibiting the differentiation of osteoclast progenitor cells into osteoclasts and, ultimately, reducing bone resorption.

Abbreviations: TGF- $\beta$, transforming growth factor $\beta$; PTHrP, parathyroid hormone-related protein; RANKL, receptor activator of NF- $\mathrm{B}$ ligand; OPG, osteoprotegerin.

growth factor $\beta$ (TGF- $\beta$ ) produced by the bone matrix increased the expression of PTHrP via Smad-dependent or Smad-independent pathways and was responsible for osteolytic lesions in breast cancer. ${ }^{74,75}$ Studies have also shown that application of $15 \mathrm{~d}-\mathrm{PGJ}_{2}$ inhibited significant enhancement of Smad2 phosphorylation as well as the nuclear levels of pSmad2 in TGF- $\beta$-stimulated cells. ${ }^{14,76}$ The addition of GW9662 to the culture media did not rescue the inhibition of PTHrP by $15 \mathrm{~d}-\mathrm{PGJ}_{2}$ regardless of TGF stimulation. ${ }^{14}$ These results indicate that $15 \mathrm{~d}-\mathrm{PGJ}_{2}$ inhibits $\mathrm{PTHrP}$ production via PPAR $\gamma$-independent and Smad2-dependent pathways, thereby regulating osteolytic metastasis.

sCommon therapeutic agents for bone metastasis include denosumab and bisphosphonates. ${ }^{77}$ Denosumab is a fully human anti-RANKL IgG2 antibody that inhibits the interaction between RANKL and RANK, thereby reducing the maturation and activity of osteoclasts. $^{78}$ Bisphosphonates are defined as "nitrogen-containing" (N-BPs: zoledronate, ibandronate) or "non-nitrogen containing" (non-N-BPs: clodronate, etidronate). ${ }^{77}$ The former is essential for the survival and activity of osteoclasts, while the latter's metabolites induce osteoclast apoptosis. ${ }^{78} 15 \mathrm{~d}$ $\mathrm{PGJ}_{2}$ affects osteoclastogenesis by reducing the production of PTHrP via a PPAR $\gamma$-independent pathway. Denosumab and bisphosphonates act through anti-RANKL and target osteoclasts, respectively. ${ }^{77,78}$ However, there is limited research on the therapeutic advantages of $15 \mathrm{~d}_{-} \mathrm{PGJ}_{2}$ compared with traditional drugs.

Osteosarcoma is a type of malignant tumor with a low survival that is uncommon and usually affects young people. ${ }^{79}$ A low patient survival rate may be associated with the high metastatic potential of cancer. ${ }^{80}$ However, the specific mechanisms that influence the progression and development of osteosarcoma are largely unknown. COX-2, which has pro-inflammatory activity, is highly expressed in primary osteosarcoma. ${ }^{81}$ Recent studies have shown that COX-2 promotes cell migration, invasion, and proliferation in human osteosarcoma cells. ${ }^{81,82}$ In one study, Kitz et al ${ }^{80}$ found that $15 \mathrm{~d}-\mathrm{PGJ}_{2}$ stimulates the expression of COX-2 via both the p38 and p42/44 mitogen-activated protein kinase (MAPK) and PPAR $\gamma$-independent signaling pathways. Polo-like kinase 1 (PLK1) is an important cell cycle 
regulator and a potential target for osteosarcoma. ${ }^{83}$ In another study, Yen et $\mathrm{al}^{84}$ found that $15 \mathrm{~d}-\mathrm{PGJ}_{2}$ promotes apoptosis through reactive oxygen species (ROS)-mediated JNK activation, which may downregulate p-Akt and protein kinase A (PKA)-PLK1 pathways. Thus, $15 \mathrm{~d}_{-}-\mathrm{PGJ}_{2}$ is a regulator of osteosarcoma and exerts cytotoxic effects through AKT and PKA-PLK1 inhibition. ${ }^{84}$ From these studies, it was concluded that $15 \mathrm{~d}-\mathrm{PGJ}_{2}$ is a potential regulator of osteosarcoma through the PPAR $\gamma$-dependent pathway.

\section{Conclusion}

Bone metabolism is an uninterrupted process that continuously removes old bone tissue and forms new bone tissue. ${ }^{28}$ Inhibition of osteoblast differentiation or enhancement of osteoclast differentiation will lead to osteoporosis, which in turn can lead to osteopetrosis. ${ }^{3}$ As an endogenous ligand for PPAR $\gamma$, the cyclopentenone prostaglandin $15 \mathrm{~d}-\mathrm{PGJ}_{2}$ plays an important regulatory role in metabolic bone diseases, RA and bone tumors through PPAR $\gamma$-dependent and independent pathways. ${ }^{9,14,23}$ It has been shown that through a PPAR $\gamma$ dependent pathway, $15 \mathrm{~d}_{-} \mathrm{PGJ}_{2}$ stimulates the differentiation of preadipocytes into adipocytes in a cell culture model system, thereby inhibiting osteoblast differentiation and affecting bone formation in bone metabolism. ${ }^{9,10}$ Many drugs with lipid-lowering effects have been used to treat the $15 \mathrm{~d}-\mathrm{PGJ}_{2}$ pathway for bone metabolism. For example, Li et $\mathrm{al}^{85}$ found that lovastatin decreased the expression of PPAR $\gamma$ but increased Cbfa1/Runx 2 gene expression, causing transformation of the unformed osteoprogenitor cells from the adipocyte differentiation pathway to the osteoblast differentiation pathway. In one study, Jiang et $\mathrm{al}^{86}$ demonstrated that pravastatin alleviated steroid-induced osteonecrosis in rats by activating the Wnt signaling pathway and inhibiting PPAR $\gamma$ expression. Studies have shown that tanshinol reduces bone formation damage by inhibiting adipogenesis via PPAR $\gamma$ signaling in glucocorticoid-induced osteoporosis rats. ${ }^{87}$ This approach may be an attractive strategy to target osteoblastic cells by specific PPAR $\gamma$ inhibitors to treat bone diseases. The effect of $15 \mathrm{~d}-\mathrm{PGJ}_{2}$ in promoting adipocyte differentiation and inhibiting osteoclast differentiation through a PPAR $\gamma$-dependent pathway is also affected by these PPAR $\gamma$ inhibitors. The above studies conclude that $15 \mathrm{~d}-$ $\mathrm{PGJ}_{2}$ plays an important regulatory role in RA, osteosarcoma, and bone metastases via a PPAR $\gamma$-independent pathway. ${ }^{14,23,80}$ Understanding the underlying mechanisms responsible for controlling the balance between osteoclastogenesis and osteoblastogenesis in human is important for regulating bone metabolism. Finally, this review summarizes the advances in the potential regulation of $15 \mathrm{~d}-\mathrm{PGJ}_{2}$ in bone metabolism and provides new therapeutic targets for osteoporosis, bone tumors, and other bone diseases.

\section{Author contributions}

All authors contributed to data analysis, drafting or revising the article, gave final approval of the version to be published, and agree to be accountable for all aspects of the work. Zhencheng Xiong and Pan Luo are co-first authors.

\section{Disclosure}

The authors report no conflicts of interest in this work.

\section{References}

1. Raggatt LJ, Partridge NC. Cellular and molecular mechanisms of bone remodeling. J Biol Chem. 2010;285:25103-25108. doi:10.1074/jbc. R109.041087

2. Wan Y. PPARgamma in bone homeostasis. Trends Endocrinol Metab. 2010;21:722-728. doi:10.1016/j.tem.2010.08.006

3. Zaidi M. Skeletal remodeling in health and disease. Nat Med. 2007;13:791-801. doi:10.1038/nm1593

4. Ali D, Abuelreich S, Alkeraishan N, et al. Multiple intracellular signaling pathways orchestrate adipocytic differentiation of human bone marrow stromal stem cells. Biosci Rep. 2018;38(1). doi:10.1042/BSR20171252.

5. Abdallah BM, Alzahrani AM, Kassem M. Secreted clusterin protein inhibits osteoblast differentiation of bone marrow mesenchymal stem cells by suppressing ERK1/2 signaling pathway. Bone. 2018;110:221-229. doi:10.1016/j.bone.2018.02.018

6. Boyce BF. Advances in the regulation of osteoclasts and osteoclast functions. J Dent Res. 2013;92:860-867. doi:10.1177/ 0022034513500306

7. Ricciotti E, FitzGerald GA. Prostaglandins and inflammation. Arterioscler Thromb Vasc Biol. 2011;31:986-1000. doi:10.1161/ ATVBAHA.110.207449

8. Straus DS, Glass CK. Cyclopentenone prostaglandins: new insights on biological activities and cellular targets. Med Res Rev. 2001;21:185-210

9. Forman BM, Tontonoz P, Chen J, et al. 15-deoxy-delta 12, 14-prostaglandin J2 is a ligand for the adipocyte determination factor PPAR gamma. Cell. 1995;83:803-812.

10. Kliewer SA, Lenhard JM, Willson TM, et al. A prostaglandin J2 metabolite binds peroxisome proliferator-activated receptor gamma and promotes adipocyte differentiation. Cell. 1995;83:813-819.

11. Takada I, Kouzmenko AP, Kato S. Wnt and PPARgamma signaling in osteoblastogenesis and adipogenesis. Nat Rev Rheumatol. 2009;5:442-447. doi:10.1038/nrrheum.2009.137

12. Viccica G, Francucci CM, Marcocci C. The role of PPARgamma for the osteoblastic differentiation. J Endocrinol Invest. 2010;33:9-12.

13. Kawai M. Adipose tissue and bone: role of PPARgamma in adipogenesis and osteogenesis. Horm Mol Biol Clin Investig. 2013;15:105-113. doi:10.1515/hmbci-2013-0036

14. Kim KR, Kim HJ, Lee SK, et al. 15-deoxy-delta12,14-prostaglandin j2 inhibits osteolytic breast cancer bone metastasis and estrogen deficiency-induced bone loss. PLoS One. 2015;10:e122764. doi:10.1371/journal.pone.0122764

15. Scher JU, Pillinger MH. 15d-PGJ2: the anti-inflammatory prostaglandin? Clin Immunol. 2005;114:100-109. doi:10.1016/j.clim.2004.09.008 
16. Ueno N, Murakami M, Tanioka T, et al. Coupling between cyclooxygenase, terminal prostanoid synthase, and phospholipase A2. J Biol Chem. 2001;276:34918-34927. doi:10.1074/jbc.M100429200

17. Kunz T, Marklund N, Hillered L, et al. Cyclooxygenase-2, prostaglandin synthases, and prostaglandin $\mathrm{H} 2$ metabolism in traumatic brain injury in the rat. $J$ Neurotrauma. 2002;19:1051-1064. doi: $10.1089 / 089771502760341965$

18. Urade Y, Eguchi N. Lipocalin-type and hematopoietic prostaglandin D synthases as a novel example of functional convergence. Prostaglandins Other Lipid Mediat. 2002;68-69:375-382.

19. Bie Q, Dong H, Jin C, et al. 15d-PGJ2 is a new hope for controlling tumor growth. Am J Transl Res. 2018;10:648-658.

20. Zhu F, Wang P, Kontrogianni-Konstantopoulos A, et al. Prostaglandin (PG)D(2) and 15-deoxy-Delta(12,14)-PGJ(2), but not PGE(2), mediate shear-induced chondrocyte apoptosis via protein kinase A-dependent regulation of polo-like kinases. Cell Death Differ. 2010;17:1325-1334. doi:10.1038/cdd.2010.13

21. Shibata T, Kondo M, Osawa T, et al. 15-deoxy-delta 12,14-prostaglandin J2. A prostaglandin D2 metabolite generated during inflammatory processes. J Biol Chem. 2002;277:10459-10466. doi:10.1074/jbc. M110314200

22. Shibata T. 15-deoxy-delta(1)(2),(1)(4)-prostaglandin J(2) as an electrophilic mediator. Biosci Biotechnol Biochem. 2015;79:1044-1049. doi:10.1080/09168451.2015.1012149

23. Kawahito Y, Kondo M, Tsubouchi Y, et al. 15-deoxy-delta(12,14)-PGJ(2) induces synoviocyte apoptosis and suppresses adjuvant-induced arthritis in rats. J Clin Invest. 2000;106:189-197. doi:10.1172/JCI9652

24. Ho TC, Chen SL, Yang YC, et al. 15-deoxy-delta(12,14)prostaglandin $\mathrm{J} 2$ induces vascular endothelial cell apoptosis through the sequential activation of MAPKS and p53. J Biol Chem. 2008;283:30273-30288. doi:10.1074/jbc.M804196200

25. Kim EH, Surh YJ. The role of 15-deoxy-delta(12,14)-prostaglandin J (2), an endogenous ligand of peroxisome proliferator-activated receptor gamma, in tumor angiogenesis. Biochem Pharmacol. 2008;76:1544-1553. doi:10.1016/j.bcp.2008.07.043

26. Fu YG, Sung JJ, Wu KC, et al. Inhibition of gastric cancer cells associated angiogenesis by $15 \mathrm{~d}$-prostaglandin $\mathrm{J} 2$ through the downregulation of angiopoietin-1. Cancer Lett. 2006;243:246-254. doi:10.1016/j. canlet.2005.11.039

27. Murata T, Aritake K, Matsumoto S, et al. Prostagladin D2 is a mast cell-derived antiangiogenic factor in lung carcinoma. Proc Natl Acad Sci U S A. 2011;108:19802-19807. doi:10.1073/pnas.1110011108

28. Hadjidakis DJ, Androulakis II. Bone remodeling. Ann N Y Acad Sci. 2006;1092:385-396. doi:10.1196/annals.1365.035

29. Muruganandan S, Roman AA, Sinal CJ. Adipocyte differentiation of bone marrow-derived mesenchymal stem cells: cross talk with the osteoblastogenic program. Cell Mol Life Sci. 2009;66:236-253. doi:10.1007/s00018-008-8429-z

30. Rosen ED, Spiegelman BM. PPARgamma: a nuclear regulator of metabolism, differentiation, and cell growth. $J$ Biochem. 2001;276:37731-37734. doi:10.1074/jbc.R100034200

31. Ge C, Zhao G, Li B, et al. Genetic inhibition of PPAR $\gamma \mathrm{S} 112$ phosphorylation reduces bone formation and stimulates marrow adipogenesis. Bone. 2018;107:1-9. doi:10.1016/j.bone.2017.10.023

32. Guan HP, Ishizuka T, Chui PC, et al. Corepressors selectively control the transcriptional activity of PPARgamma in adipocytes. Genes Dev. 2005; 19:453-461. doi:10.1101/gad.1263305

33. Zhu Y, Kan L, Qi C, et al. Isolation and characterization of peroxisome proliferator-activated receptor (PPAR) interacting protein (PRIP) as a coactivator for PPAR. $J$ Biochem. 2000;275:13510-13516. doi: $10.1074 / \mathrm{jbc} .275 .18 .13510$

34. Lefterova MI, Lazar MA. New developments in adipogenesis. Trends Endocrinol Metab. 2009;20:107-114. doi:10.1016/j.tem.2008.11.005

35. Pascual G, Fong AL, Ogawa S, et al. A SUMOylation-dependent pathway mediates transrepression of inflammatory response genes by PPAR-gamma. Nature. 2005;437:759-763. doi:10.1038/nature03988
36. Yamashita D, Yamaguchi T, Shimizu M, et al. The transactivating function of peroxisome proliferator-activated receptor gamma is negatively regulated by SUMO conjugation in the amino-terminal domain. Genes Cells. 2004;9:1017-1029. doi:10.1111/j.13652443.2004.00786.x

37. Kawai M, Green CB, Lecka-Czernik B, et al. A circadian-regulated gene, nocturnin, promotes adipogenesis by stimulating PPAR-gamma nuclear translocation. Proc Natl Acad Sci $U$ S A. 2010;107:10508-10513. doi:10.1073/pnas.1000788107

38. Baron R, Rawadi G. Targeting the Wnt/beta-catenin pathway to regulate bone formation in the adult skeleton. Endocrinology. 2007;148:2635-2643. doi:10.1210/en.2007-0270

39. Westendorf JJ, Kahler RA, Schroeder TM. Wnt signaling in osteoblasts and bone diseases. Gene. 2004;341:19-39. doi:10.1016/j. gene.2004.06.044

40. Bennett CN, Longo KA, Wright WS, et al. Regulation of osteoblastogenesis and bone mass by Wnt10b. Proc Natl Acad Sci U S A. 2005;102:3324-3329. doi:10.1073/pnas.0408742102

41. Akune T, Ohba S, Kamekura S, et al. PPAR $\gamma$ insufficiency enhances osteogenesis through osteoblast formation from bone marrow progenitors. J Clin Invest. 2004;113:846-855. doi:10.1172/ JCI200419900

42. Rachner TD, Khosla S, Hofbauer LC. Osteoporosis: now and the future. Lancet (London, England). 2011;377:1276-1287. doi:10.1016/S01406736(10)62349-5

43. Kanis JA. Diagnosis of osteoporosis and assessment of fracture risk. Lancet (London, England). 2002;359:1929-1936. doi:10.1016/ S0140-6736(02)08761-5

44. Kim SW, Her SJ, Kim SY, et al. Ectopic overexpression of adipogenic transcription factors induces transdifferentiation of MC3T3-E1 osteoblasts. Biochem Biophys Res Commun. 2005;327:811-819. doi:10.1016/j.bbrc.2004.12.076

45. Raisz LG. Pathogenesis of osteoporosis: concepts, conflicts, and prospects. J Clin Invest. 2005;115:3318-3325. doi:10.1172/JCI27071

46. Moerman EJ, Teng K, Lipschitz DA, et al. Aging activates adipogenic and suppresses osteogenic programs in mesenchymal marrow stroma/stem cells: the role of PPAR-gamma2 transcription factor and TGF-beta/BMP signaling pathways. Aging Cell. 2004;3:379-389. doi:10.1111/j.1474-9728.2004.00127.x

47. Muruganandan S, Govindarajan R, Sinal CJ. Bone marrow adipose tissue and skeletal health. Curr Osteoporos Rep. 2018;16 (4):434-442. doi:10.1007/s11914-018-0451-y

48. Tontonoz P, Spiegelman BM. Fat and beyond: the diverse biology of PPARgamma. Annu Rev Biochem. 2008;77:289-312. doi:10.1146/ annurev.biochem.77.061307.091829

49. Miyanishi K, Yamamoto T, Irisa T, et al. Bone marrow fat cell enlargement and a rise in intraosseous pressure in steroid-treated rabbits with osteonecrosis. Bone. 2002;30:185-190.

50. Yin L, Li YB, Wang YS. Dexamethasone-induced adipogenesis in primary marrow stromal cell cultures: mechanism of steroid-induced osteonecrosis. Chin Med J. 2006;119:581-588.

51. Li X, Jin L, Cui Q, et al. Steroid effects on osteogenesis through mesenchymal cell gene expression. Osteoporos Int. 2005;16:101-108. doi:10.1007/s00198-004-1649-7

52. Guo L, Chen K, Yuan J, et al. Estrogen inhibits osteoclasts formation and bone resorption via microRNA-27a targeting PPARgamma and APC. J Cell Physiol. 2018;234:581-594. doi:10.1002/jcp.26788

53. Russell RG, Xia Z, Dunford JE, et al. Bisphosphonates: an update on mechanisms of action and how these relate to clinical efficacy. Ann N Y Acad Sci. 2007;1117:209-257. doi:10.1196/annals.1402.089

54. Boyle WJ, Simonet WS, Lacey DL. Osteoclast differentiation and activation. Nature. 2003;423:337-342. doi:10.1038/nature01658

55. Kwak HB, Jin HM, Ha H, et al. Tumor necrosis factor-alpha induces differentiation of human peripheral blood mononuclear cells into osteoclasts through the induction of p21(WAF1/Cip1). Biochem Biophys Res Commun. 2005;330:1080-1086. doi:10.1016/j.bbrc.2005.03.085 
56. Hounoki H, Sugiyama E, Mohamed SG, et al. Activation of peroxisome proliferator-activated receptor gamma inhibits TNF-alphamediated osteoclast differentiation in human peripheral monocytes in part via suppression of monocyte chemoattractant protein-1 expression. Bone. 2008;42:765-774. doi:10.1016/j.bone.2007.11.016

57. Cappellen D, Luong-Nguyen NH, Bongiovanni S, et al Transcriptional program of mouse osteoclast differentiation governed by the macrophage colony-stimulating factor and the ligand for the receptor activator of NFkappa B. J Biochem. 2002;277:21971-21982. doi:10.1074/jbc.M200434200

58. Giri S, Rattan R, Singh AK, Singh I. The 15-deoxy-delta12,14prostaglandin $\mathrm{J} 2$ inhibits the inflammatory response in primary rat astrocytes via down-regulating multiple steps in phosphatidylinositol 3-kinaseAkt-NF-kappaB-p300 pathway independent of peroxisome proliferator-activated receptor gamma. J Immunol. 2004;173:5196-5208.

59. Firestein GS. Evolving concepts of rheumatoid arthritis. Nature. 2003;423:356-361. doi:10.1038/nature01661

60. Park JY, Pillinger MH, Abramson SB. Prostaglandin E2 synthesis and secretion: the role of PGE2 synthases. Clin Immunol. 2006;119 (3):229-240. doi:10.1016/j.clim.2006.01.016

61. Tsubouchi Y, Kawahito Y, Kohno M, et al. Feedback control of the arachidonate cascade in rheumatoid synoviocytes by 15-deoxy-delta (12,14)-prostaglandin J2. Biochem Biophys Res Commun. 2001;283:750-755. doi:10.1006/bbrc.2001.4847

62. Wada K, Nakajima A, Blumberg RS. PPARgamma and inflammatory bowel disease: a new therapeutic target for ulcerative colitis and Crohn's disease. Trends Mol Med. 2001;7:329-331.

63. Nakajima A, Wada K, Miki H, et al. Endogenous PPAR gamma mediates anti-inflammatory activity in murine ischemia-reperfusion injury. Gastroenterology. 2001;120:460-469.

64. Reilly CM, Oates JC, Cook JA, et al. Inhibition of mesangial cell nitric oxide in MRL/lpr mice by prostaglandin $\mathrm{J} 2$ and proliferator activation receptor-gamma agonists. J Immunol. 2000;164:1498-1504.

65. Combs CK, Johnson DE, Karlo JC, et al. Inflammatory mechanisms in Alzheimer's disease: inhibition of beta-amyloid-stimulated proinflammatory responses and neurotoxicity by PPARgamma agonists. J Neurosci. 2000;20:558-567.

66. Cheron A, Peltier J, Perez J, et al. 15-deoxy-delta12,14-prostaglandin J2 inhibits glucocorticoid binding and signaling in macrophages through a peroxisome proliferator-activated receptor gamma-independent process. J Immunol. 2004;172:7677-7683.

67. Paakinaho V, Kaikkonen S, Levonen AL, et al. Electrophilic lipid mediator 15-deoxy-delta12,14-prostaglandin j2 modifies glucocorticoid signaling via receptor SUMOylation. Mol Cell Biol. 2014;34:3202-3213. doi:10.1128/MCB.00748-14

68. Oh KS, Patel H, Gottschalk RA, et al. Anti-inflammatory chromatinscape suggests alternative mechanisms of glucocorticoid receptor action. Immunity. 2017;47(2):298-309.e295. doi:10.1016/j. immuni.2017.07.012

69. Guise TA. Molecular mechanisms of osteolytic bone metastases. Cancer. 2000;88:2892-2898.

70. Suva LJ, Washam C, Nicholas RW, et al. Bone metastasis: mechanisms and therapeutic opportunities. Nat Rev Endocrinol. 2011;7:208-218. doi:10.1038/nrendo.2010.227

71. Bendre M, Gaddy D, Nicholas RW. et al. Breast cancer metastasis to bone: it is not all about PTHrP. Clin Orthop Relat Res.2003:S39-S45. doi:10.1097/01.blo.0000093844.72468.f4
72. Karaplis AC, Goltzman D. PTH and PTHrP effects on the skeleton. Rev Endocr Metab Disord. 2000;1:331-341. doi:10.1023/A:1026526703898

73. Trouvin AP, Goëb V. Receptor activator of nuclear factor- $\kappa$ B ligand and osteoprotegerin: maintaining the balance to prevent bone loss. Clin Interv Aging. 2010;5:345-354. doi:10.2147/CIA.S10153

74. Kakonen SM, Selander KS, Chirgwin JM, et al. Transforming growth factor-beta stimulates parathyroid hormone-related protein and osteolytic metastases via Smad and mitogen-activated protein kinase signaling pathways. J Biol Chem. 2002;277:24571-24578. doi:10.1074/ jbc.M202561200

75. Safina A, Sotomayor P, Limoge M, Morrison C, Bakin AV. TAK1TAB2 signaling contributes to bone destruction by breast carcinoma cells. Mol Cancer Res. 2011;9:1042-1053. doi:10.1158/1541-7786. MCR-10-0196

76. Vaamonde-Garcia C, Malaise O, Charlier E, et al. 15-deoxy- $\Delta-12$, 14-prostaglandin $\mathrm{J} 2$ acts cooperatively with prednisolone to reduce TGF- $\beta$-induced pro-fibrotic pathways in human osteoarthritis fibroblasts. Biochem Pharmacol. 2019. doi:10.1016/j.bcp.2019.03.039

77. D’Oronzo S, Coleman R, Brown J, Silvestris F. Metastatic bone disease: pathogenesis and therapeutic options: up-date on bone metastasis management. J Bone Oncol. 2019;15:004. doi:10.1016/j. jbo.2018.10.004

78. Sousa S, Clézardin P. Bone-targeted therapies in cancer-induced bone disease. Calcif Tissue Int. 2018;102:227-250. doi:10.1007/s00223017-0353-5

79. Kansara M, Thomas DM. Molecular pathogenesis of osteosarcoma. DNA Cell Biol. 2007;26:1-18. doi:10.1089/dna.2006.0505

80. Kitz K, Windischhofer W, Leis HJ, et al. 15-deoxy-delta12,14prostaglandin $\mathrm{J} 2$ induces cox-2 expression in human osteosarcoma cells through MAPK and EGFR activation involving reactive oxygen species. Free Radic Biol Med. 2011;50:854-865. doi:10.1016/j. freeradbiomed.2010.12.039

81. Masi L, Recenti R, Silvestri S, et al. Expression of cyclooxygenase-2 in osteosarcoma of bone. Appl Immunohistochem Mol Morphol. 2007;15:70-76. doi:10.1097/01.pai.0000213131.63417.fa

82. Lee EJ, Choi EM, Kim SR, et al. Cyclooxygenase-2 promotes cell proliferation, migration and invasion in U2OS human osteosarcoma cells. Exp Mol Med. 2007;39:469-476. doi:10.1038/emm.2007.51

83. Cheng L, Wang C, Jing J. Polo-like kinase 1 as a potential therapeutic target for osteosarcoma. Curr Pharm Des. 2015;21:1347-1350.

84. Yen CC, Hsiao CD, Chen WM, et al. Cytotoxic effects of 15d-PGJ2 against osteosarcoma through ROS-mediated AKT and cell cycle inhibition. Oncotarget. 2014;5:716-725. doi:10.18632/oncotarget.1704

85. Li X, Cui Q, Kao C, et al. Lovastatin inhibits adipogenic and stimulates osteogenic differentiation by suppressing PPARgamma2 and increasing Cbfa1/Runx2 expression in bone marrow mesenchymal cell cultures. Bone. 2003;33:652-659.

86. Jiang $\mathrm{Y}$, Zhang $\mathrm{Y}$, Zhang $\mathrm{H}$, et al. Pravastatin prevents steroid-induced osteonecrosis in rats by suppressing PPARgamma expression and activating Wnt signaling pathway. Exp Biol Med (Maywood, NJ). 2014;239:347-355. doi:10.1177/1535370213519215

87. Yang YJ, Zhu Z, Wang DT, et al. Tanshinol alleviates impaired bone formation by inhibiting adipogenesis via KLF15/PPARgamma2 signaling in GIO rats. Acta Pharmacol Sin. 2018;39:633-641. doi:10.1038/aps.2017.134 


\section{Publish your work in this journal}

Drug Design, Development and Therapy is an international, peerreviewed open-access journal that spans the spectrum of drug design and development through to clinical applications. Clinical outcomes, patient safety, and programs for the development and effective, safe, and sustained use of medicines are a feature of the journal, which has also been accepted for indexing on PubMed Central. The manuscript management system is completely online and includes a very quick and fair peer-review system, which is all easy to use. Visit http://www. dovepress.com/testimonials.php to read real quotes from published authors. 